\title{
Seeing trees from space: above-ground biomass estimates of intact and degraded montane rainforests from high-resolution optical imagery
}

\author{
Mui-How Phua ${ }^{(1)}$, \\ Zia-Yiing Ling ${ }^{(1)}$, \\ David Anthony Coomes ${ }^{(2)}$, \\ Wilson Wong ${ }^{(1)}$, \\ Alexius Korom ${ }^{(1)}$, \\ Satoshi Tsuyuki ${ }^{(3)}$, \\ Keiko loki ${ }^{(1)}$, \\ Yasumasa Hirata ${ }^{(4)}$, \\ Hideki Saito ${ }^{(4)}$, \\ Gen Takao ${ }^{(4)}$
}

\begin{abstract}
Accurately quantifying the above-ground carbon stock of tropical rainforest trees is the core component of "Reduction of Emissions from Deforestation and Forest Degradation-plus" (REDD+) projects and is important for evaluating the effects of anthropogenic global change. We used high-resolution optical imagery (IKONOS-2) to identify individual tree crowns in intact and degraded rainforests in the mountains of Northern Borneo, comparing our results with 50 ground-based plots dispersed in intact and degraded forests, within which all stems $>10 \mathrm{~cm}$ in diameter were measured and identified to species or genus. We used the dimensions of tree crowns detected in the imagery to estimate above-ground biomasses (AGBs) of individual trees and plots. To this purpose, preprocessed IKONOS imagery was segmented using a watershed algorithm; stem diameter values were then estimated from the cross-sectional crown areas of these trees using regression relationships obtained from ground-based measurements. Finally, we calculated the biomass of each tree $\left(A_{G B}\right.$, in $\left.\mathrm{kg}\right)$, and the $A G B$ of plots by summation $\left(A_{G B}\right.$, in $\left.\mathrm{Mg} \mathrm{ha}^{-1}\right)$. Remotely sensed estimates of mean $A G B_{T}$ were similar to ground-based estimates in intact and degraded forests, even though small trees could not be detected from space-borne sensors. The intact and degraded forests not only had different $A G B$ but were also dissimilar in biodiversity. A tree-centric approach to carbon mapping based on high-resolution optical imagery, could be a cheap alternative to airborne laser-scanning.
\end{abstract}

Keywords: Biomass Estimation, Crown Area, IKONOS-2, Tree Community Similarity, Sabah forest ecosystems worldwide. Deforestation contributes to carbon emissions from land use changes in forests (Brown 2002), whereas forest degradation is a direct human-induced activity that leads to a longterm reduction in forest carbon stocks (IPCC 2006). In Borneo, most lowland primary forest has been lost as a result of deforestation and forest degradation over the past 40 years (Langner et al. 2012, Gaveau et al. 2014). The remaining uplands rainforests are severely threatened by increasing anthropogenic activities, particularly in the uplands of the Malaysian Bor- $\square$ (1) Faculty of Science and Natural Resources, University of Malaysia Sabah, Jalan UMS, 88400 Kota Kinabalu, Sabah (Malaysia); (2) Department of Plant Sciences, University of Cambridge, Cambridge, CB2 3EA (UK); (3) Graduate School of Agricultural and Life Sciences, The University of Tokyo, 1-1-1 Yayoi, Bunkyo-ku, Tokyo 113-8567 (Japan); (4) Forest and Forest Products Research Institute, Matsunosato 1, Tsukuba, Ibaraki 305-8687 (Japan)

@ Mui-How Phua (pmh@ums.edu.my)

Received: Aug 22, 2016 - Accepted: May 04, 2017

Citation: Phua M-H, Ling Z-Y, Coomes DA, Wong W, Korom A, Tsuyuki S, loki K, Hirata Y, Saito $H$, Takao G (2017). Seeing trees from space: above-ground biomass estimates of intact and degraded montane rainforests from high-resolution optical imagery. iForest 10: 625-634. doi: 10.3832/ifor2204-010 [online 2017-06-01]

Communicated by: Davide Travaglini neon near Indonesia, where rates of loss are ten-times greater than across the border (Broich et al. 2013).

Accurate carbon stock estimates are essential for "Reduction of Emissions from Deforestation and Forest Degradationplus" (REDD+) projects, which aims to pay governments for reductions in carbon dioxide emissions resulting from forest protection. REDD+ is regarded as a cost-effective mechanism for reducing global greenhouse gas emissions (Stern 2007), but will only function effectively if carbon savings from avoided deforestation can be calculated cheaply and reliably at high resolution (Asner et al. 2010). In the context of REDD+, forest above-ground biomass $\left(\mathrm{AGB}_{\mathrm{p}}\right.$, in $\mathrm{Mg}$ $h^{-1}$ ) is best estimated from field-based inventory datasets: stem diameter of trees within plots are measured by hand and individual tree biomass calculated from published allometric formulae, which when summed and multiplied by carbon content gives above-ground carbon density (Brown 2002). Whilst inventory plots will continue to contribute significantly to regional-scale carbon assessments, a dearth of plots in tropical regions and the expense of establishing new networks mean that analysts are increasingly looking to remote-sensing technology to measure forest stocks and changes (Brown 2002).

The ability of capturing vegetation height 
information allows airborne LiDAR to outperform optical satellite imageries in accurately mapping forest $A G B$, but it is expensive for large area application. On the other hand, recent studies demonstrate that high-resolution satellite imageries can be used to examine forest canopy structure (Wang et al. 2004, Pouliot \& King 2005). Information about individual tree crown (ITC) can be extracted by recognizing individual treetops (Wulder et al. 2002, Wang et al. 2004) and crown (Leckie et al. 2003, Wang et al. 2004, Hirata et al. 2009, Phua et al. 2014). Treetop locations are usually extracted from high resolution imagery using local maximum filtering, an approach that is most accurate for low density wood- lands where tree spacing is less than one individual per $6.6 \mathrm{~m}^{2}$ (Pitkanen 2001). Tree crowns are commonly delineated from high-resolution satellite imagery using either the watershed method (Pouliot \& King 2005, Hirata et al. 2009, Phua et al. 2014) or valley-following method (Leckie et al. 2003, Gougeon \& Leckie 2006), both of which are founded on reflectance being highest at the top of a crown and decreasing towards its edges (Culvenor 2003). Tree biomasses can be calculated from these crown area estimates. Several studies have found significant relations between imagery-estimated crown area and field-measured diameter at breast height (DBH - Leckie et al. 2005, Palace et al. 2008, Hirata et al.

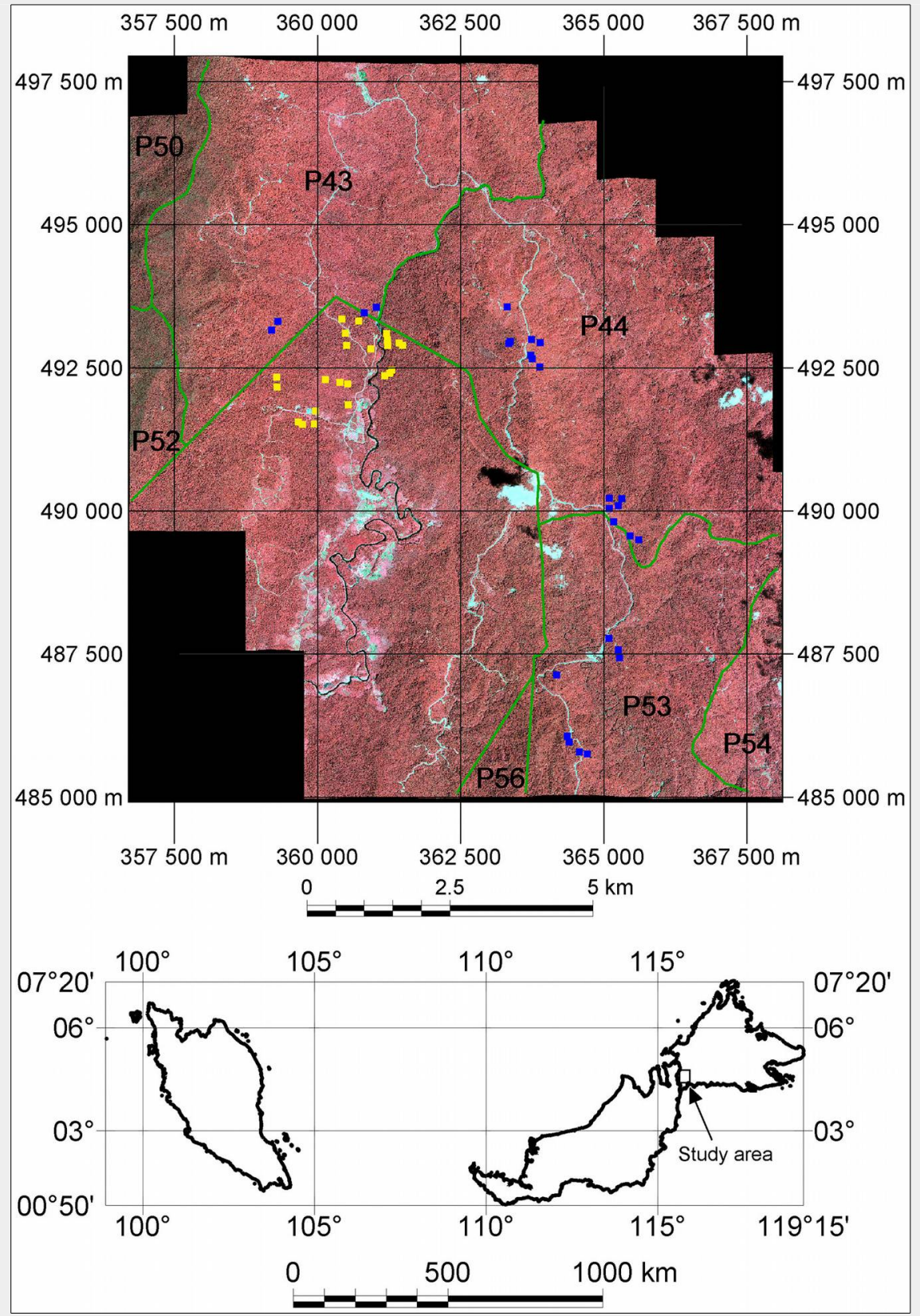

Fig. 1 - The IKONOS-2 imagery of the study area. Green line indicates compartment boundary of the Sabah Forest Industries (SFI). Polygon incuding yellow points (field plots) is land belonging to the state. Blue points are field plots collected at compartments P43, P44 and P53 within SFI concession area.
2009, Phua et al. 2014), while foresters have published many papers relating DBH to above-ground biomass (Yamakura et al. 1986, Bartelink 1996, Broadbent et al. 2008, Basuki et al. 2009, Chave et al. 2014). Thus, in principle at least, carbon density can be estimated from high-resolution satellite imagery using an approach analogous to traditional field inventory methods. However, ITC segmentation is not always very accurate, and small trees are invisible on an optical remote sensing imagery, so biases and imprecisions in carbon estimates can arise. Few studies have critically evaluated the performance of this approach for estimating tropical carbon.

Most of these remote sensing studies emphasized carbon stock estimation for REDD+, though ensuring the protection of livelihoods and biodiversity is also central to the mechanism (Gardner et al. 2012, Murray et al. 2015). There may be risks to biodiversity that arise directly or indirectly from the activities under REDD+ (VisserenHamakers et al. 2012), which needs to be monitored as co-benefits of REDD+ programmes. Monitoring tree species richness of disturbed tropical forests is complex because of high spatial heterogeneity (Sheil \& Burslem 2003), and comparisons of community similarity has thus been proposed as a robust and cost effective biodiversity index for REDD+ (Imai et al. 2012, 2014).

This study aimed to estimate the carbon density of tropical montane rainforests from the IKONOS-2 imagery, by considering forest degradation, and examining the relationship between the estimated $\mathrm{AGB}_{\mathrm{p}}$ and biodiversity to ecologically validate the $\mathrm{AGB}_{\mathrm{p}}$ estimation. We examined the correlations between crown dimension estimates extracted from the IKONOS-2 imagery (satellite-based variables) and field-derived variables for intact and degraded forest types. Here, intact forest refers to relatively intact versus degraded along a spectrum from heavily logged to reduced-impact logging and old growth forests. We tested whether the dissimilarity in community composition was closely related to dissimilarity in forest biomass within these ecosystems, as would be anticipated from succession theory; if such a link could be found then mapping $A G B$ would also allow one important aspect of forest biodiversity (namely dissimilarity to intact forest) to be mapped. Finally, a tree-level $A G B\left(A G B_{T}\right)$ distribution map was produced for the study area.

\section{Materials and methods}

\section{Study area}

The study area is part of Ulu Padas area in the northern part of Borneo, near the international border between Sabah, Malaysia and Kalimantan, Indonesia (Fig. 1). Approximately $70 \%$ of the Ulu Padas area is lower montane oak-chestnut forest, which is distributed at elevations between 1150 and $1500 \mathrm{~m}$ a.s.l. The terrain of the study area is undulating to hilly, with steep slopes espe- 
cially at the western part of the study area. Of the over 1500 specimens collected in our study area, more than one-quarter of the species correspond to the typical montane forest families of Fagaceae, Lauraceae and Guttiferae. Only seven species were from Dipterocarpaceae.

Almost half of the study area is owned by the Sabah state government, with local people (in Long Mio and Long Pasia villages) having a customary right to support their livelihoods from this land, and practicing slash-and-burn cultivation in it. Much of this state-land was selectively logged in the 1980 s and early 1990 s by commercial companies (personal communication, Head of Long Mio village, July, 2012). The other half of our study area is a concession managed by Sabah Forest Industries Sdn. Bhd. (SFI), which was established in 1983 as a government-owned company to produce pulp and paper, then privatized in 1993. SFI manages 288,623 ha of land, of which 183,346 ha are zoned as integrated timber plantations intended for the production of materials for pulp and paper. Currently about 46,000 ha of the zone is planted with Acacia and Eucalyptus species, while 104,822 ha are managed under so-called natural forest management (NFM). The harvest records of $\mathrm{SFI}$ indicate that the study area consists of an NFM area that was logged between 1997 and 2002. Since the turn of the millennium, the Sabah Forestry Department has required that NFM areas are managed using reduced impact logging methods; given the timing of the logging, it is unclear whether reduced impact logging was employed.

\section{Field data collection}

Field data were collected between November 2011 and October 2012. A total of 50 square plots of $30 \times 30 \mathrm{~m}$ were established in random locations. In 48 of these plots, all trees with a $\mathrm{DBH}>10 \mathrm{~cm}$ were characterized by measuring their $\mathrm{DBH}$, height and tree position. The remaining two plots consisted mostly of small trees, so all stems with $\mathrm{DBH}>5 \mathrm{~cm}$ were measured. The plot coordinates were determined by post-processing of differential GPS data (Ashtech ProMark $100^{\circledast}$, Spectra Precision, Westminster, CO, USA). Tree height was measured using TruPulse laser range finder. The tree positions were measured in $\mathrm{XY}$ distance using TruPulse or distometer relative to the plot's boundary. Of the 50 plots, 27 were located within the NFM areas, and the remainder in the state land. In total, 3709 trees were measured in these plots.

The forests were classified into two categories - intact and degraded forests based on field assessment of forest condition, floristic composition and land use activities. The land use history was obtained from interviews with local villagers and forest management data of the SFI. Reduced impact logging areas and village reserve forest were categorized as intact, whereas slash-and-burn cultivation and conventional logging areas were categorized as degraded. Whilst forests subjected to reduced-impact logging are likely to exhibit lower biomass than old-growth forest, their recovery can be remarkably rapid (Sheil \& Burslem 2003) and the species composition is much more similar to oldgrowth forest than that of conventionally logged forest (Imai et al. 2012); for this reason we include them in the intact forest category. In addition, patches with AGB exceeding $200 \mathrm{Mg} \mathrm{ha}^{-1}$ were classified as intact forest; this threshold is widely used to differentiate intact and degraded tropical forests (Asner 2002, Morel et al. 2012).

We used allometric equations developed specifically for Bornean rainforest trees (Yamakura et al. 1986, Basuki et al. 2009, Kenzo et al. 2009). The AGB (kg) of trees in intact forests was calculated from $\mathrm{DBH}$ $(\mathrm{cm})$ as follows (eqn. 1):

$$
A G B_{T(\text { intact forest })}=\exp (2.62 \cdot \ln D B H-2.30)
$$

using a regression relationship obtained for lowland rainforest by Yamakura et al. (1986). This equation gives biomasses approximately $25 \%$ above those obtained by the wood-density corrected allometric model of Chave et al. (2014) based on a global dataset. In degraded forests the following relationship, developed for this type of forest (Kenzo et at. 2009), was used (eqn. 2):

$$
A G B_{T(\text { degraded forest })}=0.0829 \cdot D B H^{2.43}
$$

Biomass predictions from this formula are approximately half that given by the intact forest equation, because the early successional species found in these sites have much lower wood density $(\sim 0.35$ compared to 0.36-0.81 - Zanne et al. 2009).

\section{Atmospheric and topographic} correction of satellite imagery

An IKONOS-2 imagery acquired on 28 February 2010 was used in this study. Orthorectification was conducted using the rational polynomial coefficients file and the 30$\mathrm{m}$ resolution Digital Elevation Model of the Shuttle Radar Topography Mission (SRTMDEM) without ground control point (GCP). The ortho-rectification was assessed by calculating Root Mean Square (RMS) Residual from GCPs when compared to a Digital Surface Model generated from airborne LiDAR data. The RMS Residual was $1.13 \mathrm{~m}$. IKONOS-2 has four multi-spectral bands of 4-m resolution. The panchromatic band of IKONOS-2 has a spatial resolution of $1 \mathrm{~m}$. The spectral radiance of the multi-spectral and panchromatic bands was calculated using the published calibration values.

Atmospheric correction aims at removing the scattering and absorption (Vermote et al. 1997). The scattering effect - mainly due to path radiance - was corrected using the dark object subtraction method (Chavez 1988); the dark object value for each band was determined by examining the lower end of each histogram: the influence of haze is indicated by a sharp increase in the number of pixels at nonzero radiance (Chavez 1988).

In the hilly study area, the brightness values of pixels vary as a result of differences in shading. These effects were reduced by topographic normalization of the IKONOS2 imagery, using a non-Lambertian method with a Minnaert constant (Smith et al. 1980). We resampled the SRTM digital elevation model to the IKONOS-2 imagery's resolution to derive the slope and aspect for the correction. The Minnaert coefficient $k$ describes the surface's bi-directional reflectance distribution function, where the scattering depends on the surface roughness (Smith et al. 1980). The value of $k$ varies between 0 and 1 , with 1 representing a perfectly diffuse reflector and a small value representing anisotropic scattering specific to the scene. The pixels of the intact forest were sampled to determine the values of $k$ using linear regression analysis, and a backward radiance correction carried out (Smith et al. 1980).

\section{Tree crown delineation}

The geo- and atmospherically corrected IKONOS imagery were further processed before applying a tree-top recognition algorithm. First, we used principal component pan-sharpening to combine the four multispectral bands of 4-m resolution with the 1-m panchromatic band. A mask was then generated to filter non-vegetated areas (bare land, clouds and cloud shadows) from the vegetation we wished to segment. The mask was created by manually thresholding the normalized difference vegetation index (NDVI) from the IKONOS imagery to distinguish vegetation from non-vegetation areas, and removing shadows using the panchromatic band (Asner \& Warner 2003). Finally, inverse image of the pan-sharpened image was generated. The inverted pan-sharpened image was input into a watershed algorithm to delineate individual tree crowns (Hirata et al. 2009). All these analyses were conducted in ArcGIS $9^{\circledast}$ (ESRI, Redwood, CA, USA). The polygons delineated using the watershed method were overlaid with the plot location to determine the crown polygons for each plot. The segmentation results were compared with the tree positions from the plot data to evaluate the crown delineation in each plot; polygons with centroid within a plot were considered as trees within that plot. Because lower canopy trees cannot be observed by the satellite sensor, we applied the general principle that considers tree crowns spotted in high-resolution satellite data are most likely to correspond with the largest trees observed in the plot (Palace et al. 2008, Hirata et al. 2009). Say that $n$ trees are delineated from the imagery in a given plot; if the stems measured in the plot are ranked from largest to the smallest based on $\mathrm{DBH}$, then the first $n$ trees in the ranking are likely to corre- 
Tab. 1 - Characteristics of the delineated tree crowns for intact and degraded forests (50 plots).

\begin{tabular}{llrrrrr}
\hline Forest Type & Characteristics & Minimum & Maximum & Mean & Std. Error & Std. Deviation \\
\hline Intact forest & Closeness index $(\%)$ & 0.28 & 0.93 & 0.49 & 0.25 & 0.17 \\
(26 plots) & Field-derived DBH $(\mathrm{cm})$ & 10.40 & 122.10 & 29.73 & 0.53 & 14.86 \\
& Field-derived Height $(\mathrm{m})$ & 7.60 & 65.90 & 23.15 & 0.27 & 7.55 \\
& Tree density $\left(\mathrm{n} \mathrm{ha}{ }^{-1}\right)$ & 300.00 & 1077.78 & 605.13 & 29.82 & 152.06 \\
Degraded forest & Closeness index & 0.16 & 0.78 & 0.39 & 0.31 & 0.15 \\
(24 plots) & Field-derived DBH $(\mathrm{cm})$ & 10.10 & 80.80 & 20.90 & 0.27 & 7.60 \\
& Field-derived Height $(\mathrm{m})$ & 5.10 & 41.80 & 18.47 & 0.18 & 5.12 \\
& Tree density $\left(\mathrm{n} \mathrm{ha}^{-1}\right)$ & 355.56 & 3850.00 & 1220.72 & 158.72 & 775.30 \\
\hline
\end{tabular}

spond to the remotely sensed trees. Along with the ranked trees, we compared the tree position and measured crown size between a delineated crown and field measured crown. We discarded any delineated crown that was a sub-crown or included several crowns.

Crown delineation accuracy was assessed by comparing automatically and manually segmented imageries (Clinton et al. 2010). A total of 1104 upper-canopy crowns within 35 plots were visually interpreted and digitized to assess the delineation accuracy. The simplest test of segmentation accuracy is to compare the number of "reference crowns" (i.e., those manually segmented) with the number of automatically segmented crowns. Secondly, the degree of spatial overlap between crowns can be determined. The degree to which automatically and manually delineated crown areas overlap was used to calculate the over-segmentation index (eqn. 3):

$$
O S=1-\frac{\operatorname{area}\left(x_{i} \cap y_{j}\right)}{\operatorname{area}\left(x_{j}\right)}
$$

where OS is the oversegmentation index (poor $=1$, excellent $=0$ ), $X=\left\{x_{i}: i=1, \ldots, n\right\}$ and $Y=\left\{y_{j}: j=1, \ldots, n\right\} . X$ are the automatically delineated crowns and $Y$ are the largest $n$ reference crowns. For under-segmentation (US), it was calculated as fol- lows (eqn. 4):

$$
U S=1-\frac{\operatorname{area}\left(x_{i} \cap y_{j}\right)}{\operatorname{area}\left(y_{j}\right)}
$$

The overall quality of segmentation is then given by the closeness index $(D-$ eqn. 5):

$$
D=\sqrt{O S^{2}+U S^{2}}
$$

Lower values of $D$ indicate better segmentation results.

\section{Estimation of the above-ground}

biomass of trees and carbon density

Segmentation of the IKONOS-2 imagery generated three crown related variables: crown perimeter ( $C P \_$I) and crown area (CA I), and the crown diameter calculated from the crown area using a circular shape formula (CD_I). Pearson's correlation was used to test which of these variables was most closely related to field-derived AGB (or structural variables), and then this variable was used to create a statistical estimation model by least squares regression. Half the plots with delineated tree crown data were selected at random for model building, whilst the other half were kept for model validation. The estimated tree$A G B$ was compared with the observed tree-AGB from the field measurements.

Tab. 2 - Correlations between the satellite-based ( $I$ ) and field-derived ( $f$ ) estimates of individual tree characteristics for the intact and degraded forests. (CA_I): Satellitebased crown area; $(C P$ I): satellite-based crown perimeter; $(C D$ I): satellite-based crown diameter; ( $\mathrm{Ht} f$ ): field-derived tree height; ( $\mathrm{DBH}$ f): field-derived stem diameter; (AGB_f): field-derived above ground biomass. (**): Correlation is significant at the 0.01 level (2-tailed).

\begin{tabular}{llllllll}
\hline Forest Type & Estimates & CA_I & CP_I & CD_I & Ht_f & DBH_f & AGB_f \\
\hline Intact forest & CA_I & 1 & - & - & - & - & - \\
(396 trees in 13 & CP_I & $0.943^{* *}$ & 1 & - & - & - & - \\
plots) & CD_I & $0.981^{* *}$ & $0.960^{* *}$ & 1 & - & - & - \\
& Ht_f & $0.547^{* *}$ & $0.531^{* *}$ & $0.572^{* *}$ & 1 & - & - \\
& DBH_f & $0.871^{* *}$ & $0.836^{* *}$ & $0.862^{* *}$ & $0.676^{* *}$ & 1 & - \\
& AGB_f & $0.734^{* *}$ & $0.669^{* *}$ & $0.685^{* *}$ & $0.548^{* *}$ & $0.915^{* *}$ & 1 \\
Degraded forest & CA_I & 1 & - & - & - & - & - \\
(390 trees in 12 & CP_I & $0.946^{* *}$ & 1 & - & - & - & - \\
plots) & CD_I & $0.976^{* *}$ & $0.962^{* *}$ & 1 & - & - & - \\
& Ht_f & $0.509^{* *}$ & $0.501^{* *}$ & $0.514^{* *}$ & 1 & - & - \\
& DBH_f & $0.811^{* *}$ & $0.772^{* *}$ & $0.789^{* *}$ & $0.684^{* *}$ & 1 & - \\
& AGB_f & $0.711^{* *}$ & $0.639^{* *}$ & $0.639^{* *}$ & $0.486^{* *}$ & $0.879^{* *}$ & 1 \\
\hline
\end{tabular}

\section{Tree community composition}

We initially identified species of all trees on the plots by local names. Plant specimens were then taken for identification at the herbarium of the Forest Research Center in Sandakan, Sabah. We used nonmetric multidimensional scaling (NMDS) to analyze the variation in tree community composition among plots (Imai et al. 2012, 2014), which is a nonparametric method giving ecologically meaningful measures of community dissimilarity. The relative basal area of each species in 50 plots was used to calculate the dissimilarity among plots (Chao et al. 2005). Differences among tree communities were examined by looking at the first and second axes of variation from the ordination analysis; differences among forest types were analyzed by permutational multivariate analysis of variance (PERMANOVA - Anderson 2001), using the "adonis" function in the "vegan" package of R (Oksanen et al. 2013).

\section{Results}

\section{Tree crown delineation}

A total of 1584 upper-canopy tree crowns were detected within the 50 plots (Tab. 1), which is almost half of the total number of trees measured on the ground, suggesting that the majority of trees were hidden under the canopy. The closeness index (D) to the reference tree crowns was 0.36 (i.e., the accuracy of segmentation was $64 \%$ ). Delineation rate varied between forest types: it was on average $49 \%$ accurate (range $28-93 \%$ ) in intact forest, where trees were large and densities low, but only $39 \%$ accurate (range 16-78\%) in degraded forest where there were many small trees and lianas. The upper-canopy trees we detected had mean DBH $=29.7 \mathrm{~cm}( \pm 1$ standard error of mean of $14.9 \mathrm{~cm}$ ) and mean height of $23.2 \pm 7.6 \mathrm{~m}$ in intact forest. Detected trees were much smaller in the degraded forest, with a mean DBH of 20.9 $\pm 7.6 \mathrm{~cm}$ and mean height of $18.5 \pm 5.1 \mathrm{~m}$.

Crown dimension estimates of the detected trees were compared to field-derived variables (Tab. 2). For the intact forest, most of the field-derived variables were significantly correlated with the satellite-based variables: DBH was highly correlated with remotely sensed crown dimension variables (CA_I: $r=0.87 ; C D \_$I: $r=0.86$; 
Fig. 2 - DBH estimation models using CA I for the intact

(a) and degraded (b) forests. Crown area was well correlated with $\mathrm{DBH}$, especially below $50 \mathrm{~cm}$. Considerable variations were observed for $\mathrm{DBH}>60 \mathrm{~cm}$. A few old trees with large $\mathrm{DBH}$ (in the dashed circle in panel a) have relatively small crown areas. This reflects the typical condition of an intact tropical rainforest.
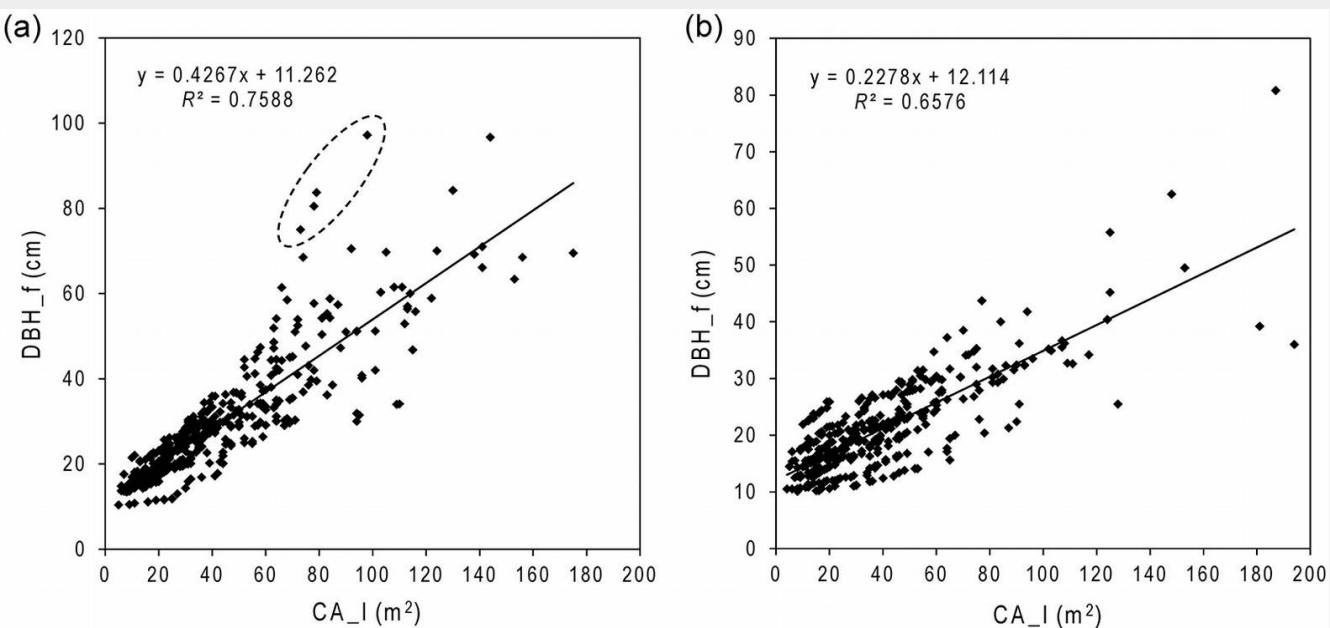

Fig. 3 - Observed vs. estimated DBH for the intact (a) and degraded (b) forests.

Overall, DBH was very well estimated by the models for both forests. However, larger trees $(\mathrm{DBH}>50 \mathrm{~cm}$ for intact and $\mathrm{DBH}>35 \mathrm{~cm}$ for degraded forests) seemed to be under-estimated.

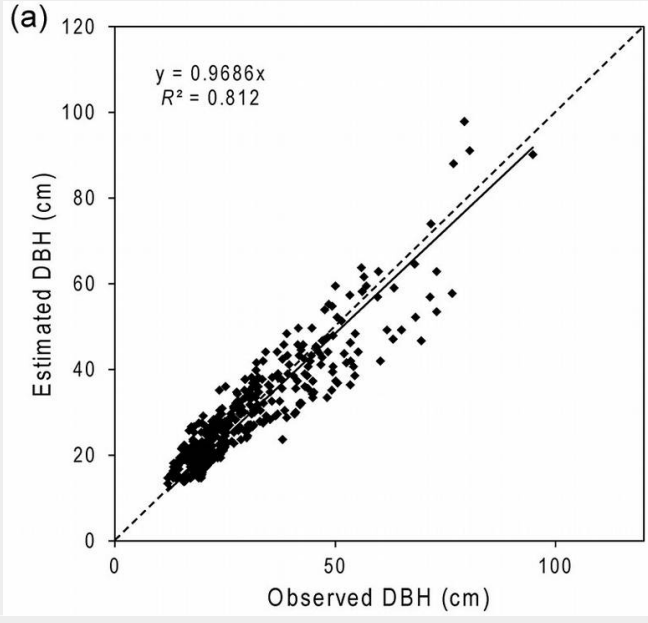

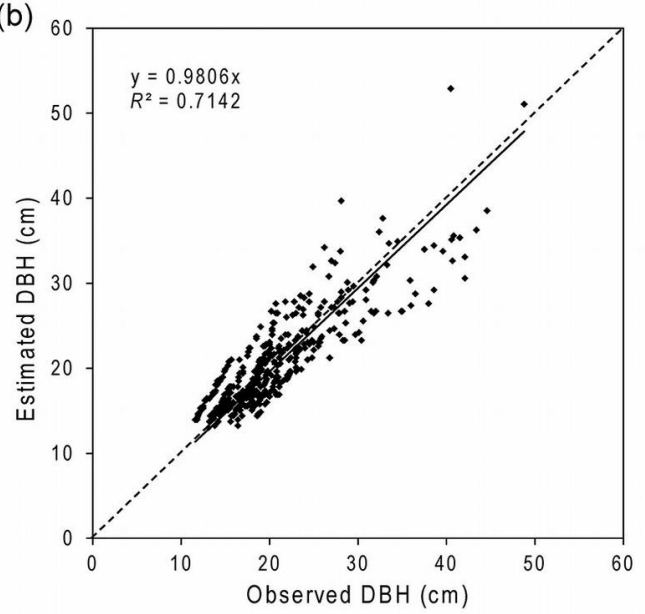

CP I: $r=0.84$ ), but field-derived tree height ( $\left.\mathrm{Ht}_{-} \mathrm{f}\right)$ was more weakly correlated with satellite-based variables ( $r$ ranging from 0.53 to 0.57 ). Field-derived AGB was moderately correlated with CA I $(r=0.73), C D$ I $(r=0.69)$ and CP I $(r=0 . \overline{6} 7)$. Similarly correlations were found for the degraded forest: DBH was highly correlated with the satellite-based variables CA_I $(r=0.81)$, $C D \perp(r=0.79)$ and $C P$ I $(r=0.77)$, while tree height was less well correlated with them. Similarly, we only found moderate correlations between field-derived AGB and with the three satellite-based variables ( $r$ value 0.64-0.71).
Based on these correlation analyses, the best-performing satellite-based variable (CA I) was used as the independent variable in regression models, which was then used to estimate DBH of all upper-canopy trees in the intact and degraded forests. With field measurements, we found that polynomial $\left(R^{2}=0.68\right)$ and linear $\left(R^{2}=0.67\right)$ regression functions only differed by $1 \%$. Therefore, we used a straight line relationship to estimate DBH from CA_I $\left(\mathrm{m}^{2}\right)$. $\mathrm{DBH} f$ and $C A$ I exhibited a strong positive biophysical relationship $\left(R^{2}=0.76\right.$ and 0.66 in intact and degraded forests, respectively - Fig. 2). The regression models for esti-

Tab. 3 - Validation of DBH and tree AGB estimation for intact and degraded forests (based on independent 25 plots of validation dataset).

\begin{tabular}{llrrrrr}
\hline Forest Type & Parameter & Min & Max & Mean & Std. Error & Std. Deviation \\
\hline Intact forest & CA_I $\left(\mathrm{m}^{2}\right)$ & 5.00 & 203.00 & 43.34 & 1.54 & 30.32 \\
(387 trees in 13 & Observed DBH $(\mathrm{cm})$ & 12.00 & 94.80 & 29.74 & 0.73 & 14.34 \\
plots) & Estimated DBH $(\mathrm{cm})$ & 13.40 & 97.88 & 29.78 & 0.66 & 12.94 \\
& Observed AGB $\left(\mathrm{kg} \mathrm{tree}^{-1}\right)$ & 67.39 & 15148.18 & 1125.51 & 86.96 & 1708.46 \\
& Estimated AGB $\left(\mathrm{kg} \mathrm{tree}^{-1}\right)$ & 89.90 & 16472.72 & 1058.00 & 86.30 & 1695.48 \\
Degraded forest & CA_I (m $\left.{ }^{2}\right)$ & 4.00 & 179.00 & 36.90 & 1.27 & 25.65 \\
$(410$ trees in 12 & Observed DBH $(\mathrm{cm})$ & 11.60 & 48.80 & 20.55 & 0.33 & 6.55 \\
plots) & Estimated DBH $(\mathrm{cm})$ & 13.03 & 52.89 & 20.57 & 0.29 & 5.85 \\
& Observed AGB $\left(\mathrm{kg} \mathrm{tree}^{-1}\right)$ & 32.00 & 1050.55 & 152.01 & 7.03 & 142.01 \\
& Estimated AGB $\left(\mathrm{kg} \mathrm{tree}^{-1}\right)$ & 42.41 & 1277.49 & 147.34 & 6.31 & 127.39 \\
\hline
\end{tabular}



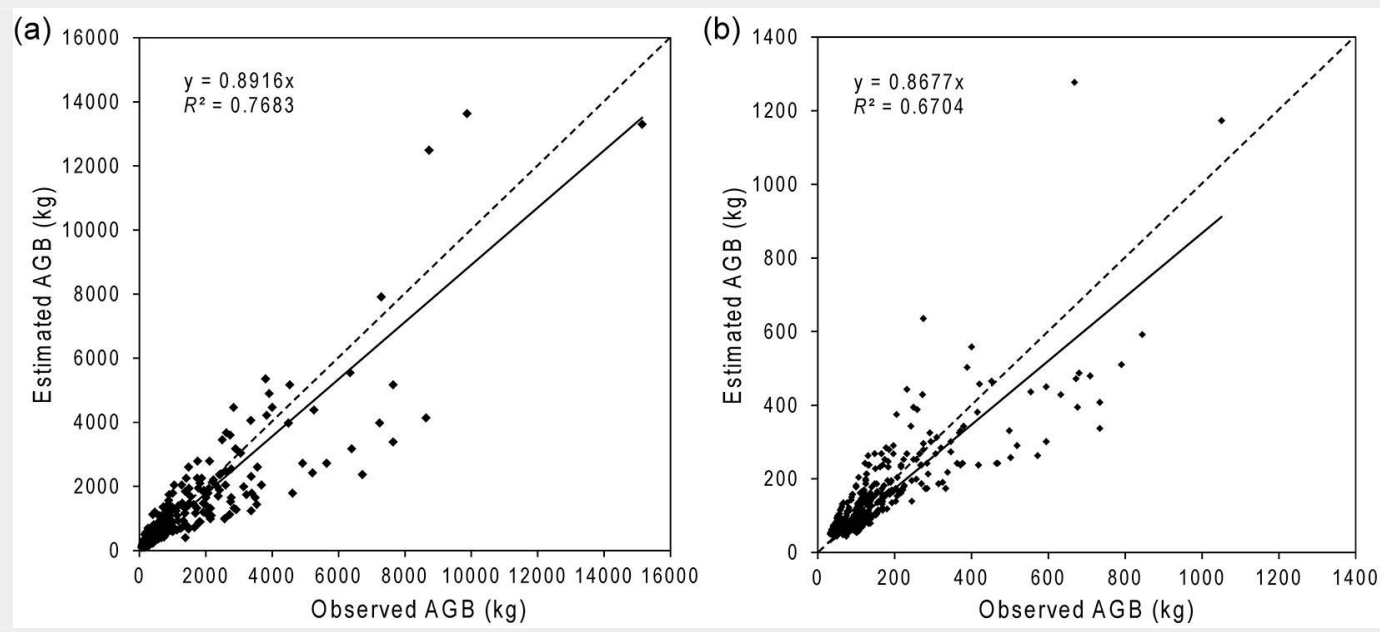

Fig. 4 - Observed vs. estimated tree AGB for the intact (a) and degraded (b) forests. The underestimation of DBH for larger trees had led to under-estimation of $A G B$ for those trees.

Tab. 4 - Root-mean-square error (RMSE) of the AGB estimation for intact and degraded forests (based on 25 independent plots in the validation dataset). Average estimation was calculated as percent of the estimated $A G B$ to the observed total AGB.

\begin{tabular}{lrc}
\hline Parameter & $\begin{array}{r}\text { Intact } \\
\text { forest }\end{array}$ & $\begin{array}{c}\text { Degraded } \\
\text { forest }\end{array}$ \\
\hline RMSE (Mg ha-1 $)$ & 134.7 & 20.3 \\
RMSE (\%) & 33.9 & 30.4 \\
Average estimation (\%) & -7.7 & -20.7 \\
\hline
\end{tabular}

also highly statistically significant $\left(F_{[1,387]}=\right.$ $743, p<0.0001$ ).

Plots of observed vs. estimated DBH for the intact and degraded forests with validation datasets (Fig. 3a, Fig. 3b) had slopes of 0.97 and 0.98 , when forced through the origin, demonstrating that they were virtually unbiased. The mean of the observed $\mathrm{DBH}$ values was very similar to the mean of the estimated values (Tab. 3).

Estimation of above-ground biomass of individual trees

Tree $\mathrm{AGB}_{\mathrm{T}}$ calculated from estimated $\mathrm{DBH}$ values were very similar to the observed
$\mathrm{AGB}_{\mathrm{T}}$ for the intact and the degraded forests (Tab. 3). For the intact forest, the estimated $A_{G G} B_{T}$ ranged between $90 \mathrm{~kg}$ and $16,473 \mathrm{~kg}$, with a mean of $1,058 \mathrm{~kg}$, which was approximately $6 \%$ lower than the observed $A G B_{T}$ for the intact forest. Both the minimum and maximum of the estimated $A G B_{T}$ for the degraded forest were much lower than the intact forest: only 42 $\mathrm{kg}$ and $1,277 \mathrm{~kg}$. The mean estimated $\mathrm{AGB}_{\mathrm{T}}$ of the degraded forest was $147 \mathrm{~kg}$, which was about $3 \%$ lower than the observed $A G B_{T}$. Regressions of observed $v s$. fitted values (through the origin) had a slope of 0.89 and 0.87 for intact and degraded forests, respectively (Fig. 4).

$A G B_{p}$ values were calculated by summing the $\mathrm{AGB}_{\mathrm{T}}$ of all trees delineated per plot and converting to $\mathrm{Mg}$ per hectare. The field-derived $A G B_{p}$ for intact and degraded forests were under-estimated by about 10\% and $20 \%$ (Tab. 4), which is greater than the under-estimation individual tree AGB. This additional biomass arises because smaller trees were not visible in the imagery, and although they individually have low $A G B_{T}$ they are numerous. RMSE of the estimates were 135 and $20 \mathrm{Mg} \mathrm{ha}^{-1}$ for intact and degraded forests, respectively, representing 34\% and 30\% of the average observed $A G B_{p}$.
Biodiversity similarity between intact and degraded forests

The first axis of the biodiversity ordination accounted for $53 \%$ of the total variation, reflecting a major proportion of dissimilarity among communities. There is a significant relationship between groundbased estimates of $A G B_{p}$ (i.e., an indicator of forest degradation) and NMDS axis 1 scores (Fig. 5a). Similar patterns were observed when plotting the imagery-estimated $A G B_{p}$ against the NMDS axis 1 scores (Fig. 5b). Intact and degraded forests are clearly differentiated by NMDS: almost all (92\%) of the degraded forest plots had a positive axis-1 score, whilst most $(85 \%)$ of the intact forest plots had a negative score on the NDMS axis 1.

The above-ground biomass distribution maps

Object-based classification approach with the nearest-neighbour classifier was used in eCognition software (Trimble) to classify the segmented IKONOS-2 imagery into intact and degraded forests using field observations of the forest structure, species composition and land use history to train the classifier. The NMDS results (Fig. 5a) were used to calculate overall accuracy and kappa statistic. Comparing these classifica-
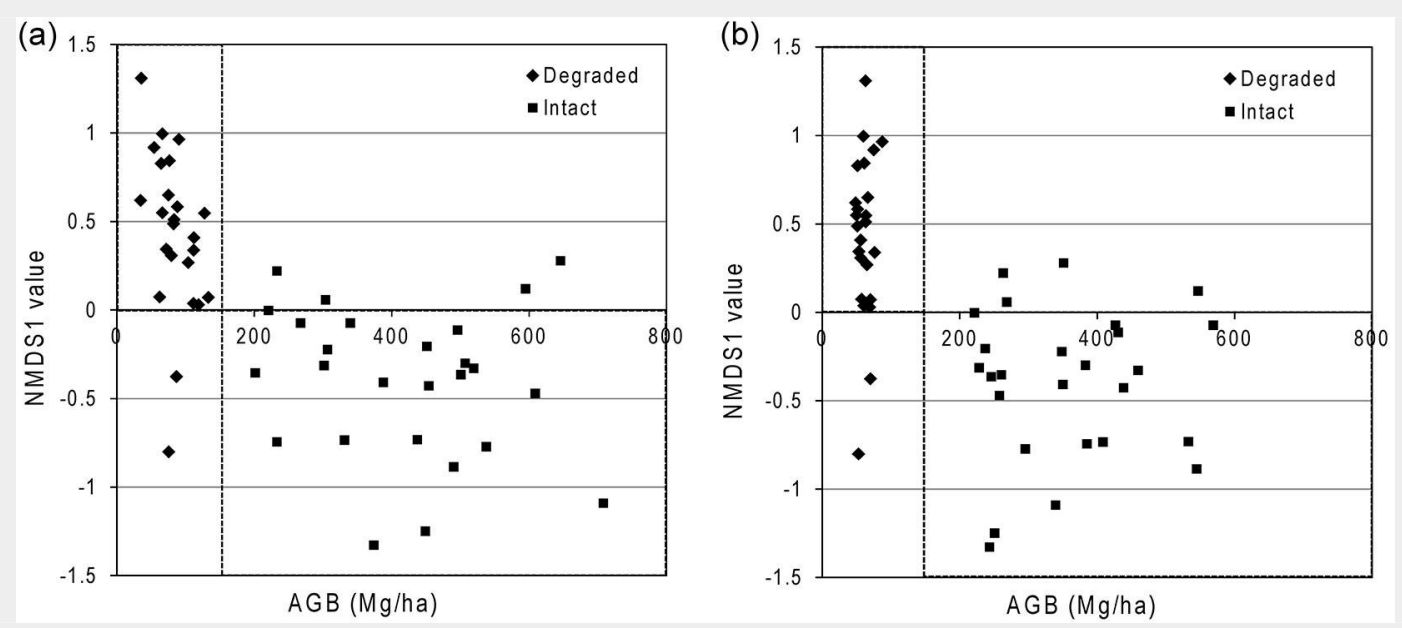

Fig. 5 - Relationships between $A G B_{p}$ and NMDS1 for (a) field measured and (b) remotely sensed $A G B_{p}$. 
tions with the field plot data, the overall accuracy and kappa statistic of the forest type classification were $82.0 \%$ and 0.64 , respectively. The producer's and user's accuracies for the intact and degraded forests ranged between $75 \%$ and $88 \%$. The forest type classification from the IKONOS-2 imagery indicated that the study area had 7036 ha of intact forest. Degraded forest covered about half the area of intact forest (3542 ha).

Fig. 6 shows the AGB distribution of the montane forests at the Ulu Padas area at tree level. To produce the $A G B_{T}$ map, eqn. 6 and eqn. 7 were used to estimate DBH for the intact and degraded forest trees in the segmented imageries, and then $A G B_{T}$ was calculated using the appropriate biomass allometries, i.e., eqn. 1 (Yamakura et al. 1986) and eqn. 2 (Kenzo et al. 2009) for intact forest and degraded forests, respectively. The map shows a strong influence of land-use activity on the spatial distribution of $\mathrm{AGB}_{\mathrm{T}}$ (Fig. 6). Most of the trees in the intact forest possess a large crown and thus have a high $\mathrm{AGB}_{\mathrm{T}}$ (more green and yellow colored polygons in Box A of Fig. 6). In contrast, most of the trees in the degraded forest were of a dark shade of blue color, indicating a lower $A G B_{T}$ (Box $B$ in Fig. 6). The high $A G B_{T}$ in the intact forest was mainly found at forests subject to reduced impact logging operation, whereas the low $A G B_{T}$ in degraded forest in the stateland was mainly due to shifting cultivation activities.

\section{Discussion}

\section{Tree centric approaches to biomass} mapping

Optical imagery collected by satellites has long been regarded as unsatisfactory for the purposes of estimating the biomass or degradation status of tropical rain forest, because indices such as NDVI, based on the spectral characteristics of pixels, are known to saturate at high biomass (Phua \& Saito 2003, Lu 2005, Langner et al. 2012). Here we show that recognizing individual trees from high-resolution optical imagery can overcome these problems. Crown area has proven to be a robust and sensitive variable for estimating $\mathrm{DBH}$ - and thence biomass - because of the linear relationship between crown area and $\mathrm{DBH}$ in both intact and degraded forests (Phua et al. 2014).

Overall, DBH estimation models for intact and degraded montane rainforests in northern Borneo were successful. The estimated $\mathrm{AGB}_{\mathrm{P}}$ has a mean of $647 \mathrm{Mg} \mathrm{ha}^{-1}$ and $176 \mathrm{Mg} \mathrm{ha}{ }^{-1}$ for the intact and degraded forests, respectively. The small differences between the means of the estimated and observed $A_{G B}$ for both forest types provided a convincing argument that the results of the satellite-based approach were consistent, overall. The scatter-plots between the estimated and observed values of AGB at tree level (Fig. 4) and plot level

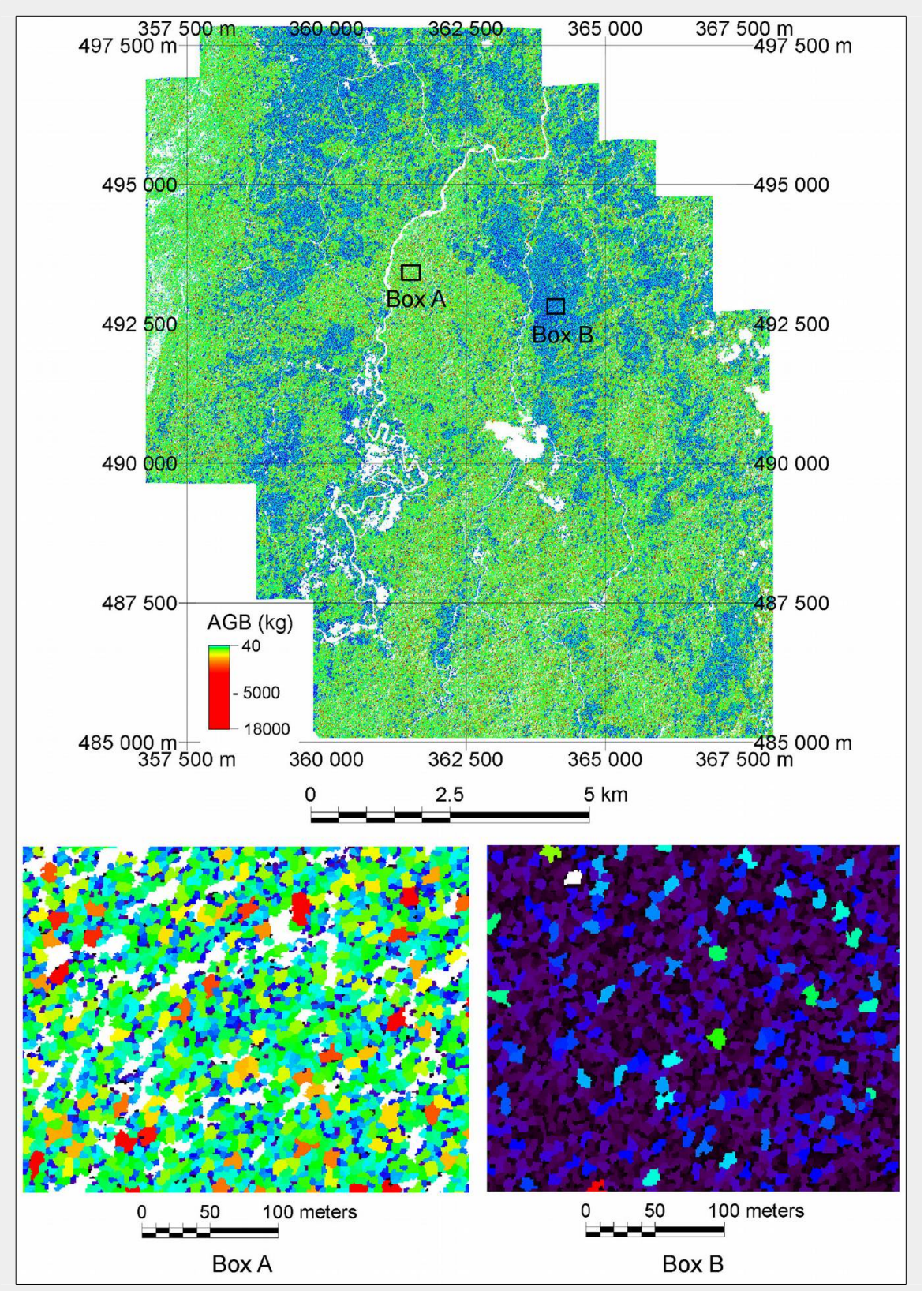

Fig. 6 - Above-ground biomass $\left(A G B_{T}\right)$ map of the study area. $A G B_{T}$ of trees $(\mathrm{kg})$ were assessed through DBH estimation by forest type. Boxes $A$ and $B$ are magnified areas of $A G B_{T}$ for the intact and degraded forests. Box $A$ shows a typical area logged with reduced impact logging method, whereas Box B shows an example of regenerated forest at a shifting cultivation area.

(Fig. 5) for both forest types confirmed the consistency of the estimation models. The RMSE for intact and degraded forests were $34 \%$ and $30 \%$ of the average observed $A_{G B}$, respectively. We also examined factors that affect the RMSE by analyzing the squared residual of the estimates against tree density per hectare and total AGB. Three outlier plots (Fig. 5), representing $12 \%$ of the validation plots, with high squared residuals were low in tree density but very high in total $A G B_{p}$. This was due to the presence of few old, big trees (DBH > $80 \mathrm{~cm}$ ) with relatively small crowns. Nevertheless, the slopes of the regression lines through the origins for the scatter-plots in Fig. 4 (degraded: $y=0.87 \cdot x$; intact: $y=$
$0.89 \cdot x)$ indicated that $\mathrm{DBH}$ estimation by considering forest degradation had a better fit compared with the combined forest types $(y=0.74 \cdot x-$ Phua et al. 2014). Moreover, the two forest types were clearly different in terms of the statistics of DBH as well as AGB (Tab. 3).

Because of the extraordinary accuracy of airborne LiDAR in measuring canopy height, laser scanning is the best current technology for estimating the carbon density of tropical forests. Asner \& Mascaro (2014) have shown that simple regression relationships based on LiDAR estimates of mean canopy height can provide highly accurate carbon maps $\left(R^{2}>0.8\right)$, and can be applied to different regions of the world 
once adjusted for variation in wood density and forest packing. Airborne LiDAR surveys outperform spaceborne optical surveys: in Malaysian montane forests the RMSE of AGB estimates made by LiDAR was $26 \%$ of average AGB (loki et al. 2014), which is about $8 \%$ and $4 \%$ lower than the results presented here for degraded and intact forests. However, provided that space-borne sensors can deliver unbiased estimates of $A G B$, they could be valuable at regional scales, even if any given pixel is measured at lower precision than possible from an aircraft. This is appealing, given the high cost of LiDAR data acquisition. In addition, a new generation of small satellites with optical sensors are being launched that will collect data much more frequently than the current earth observation satellites and should thereby overcome many of the problems associated with persistent cloud cover in the tropics.

Recently, Dalponte \& Coomes (2016) suggested that a tree-centric approach based on LiDAR imagery, based on fundamental principles of forest mensuration, can deliver results with a similar precision to the top-canopy-height method. Airborne LiD$A R$ delivers more precise results because it measures both canopy height and canopy area, whereas the optical imagery only delivers canopy area information, and also because the $3 \mathrm{D}$ point cloud contains much richer structural information than the optical sensors. Future research could focus productively on using tree-centric airborne LiDAR approaches to better calibrate the spaceborne optical sensor approach described in this paper. The relationships between satellite-based crown variables and tree structural variables in a tropical forest also require further investigation. $\mathrm{DBH}$ is known to have a strong relationship with crown area (Bartelink 1996) and crown diameter (Song et al. 2010) in temperate forests, and a significant relationship has been found for an intact forest in Brazil (Palace et al. 2008), and in a montane forest in Malaysia (Phua et al. 2014). However, a comprehensive analysis has yet to be published.

\section{Biodiversity mapping in the context of REDD+}

We have shown that optical imagery can differentiate between intact and degraded montane rainforests. This is important in the context of REDD+. Linking biodiversity monitoring to carbon stock estimation is vital for effective implementation of REDD+, but even more critical is what aspect of biodiversity needs to be monitored (Dickson \& Kapos 2012). Tree community composition is consistent in describing biodiversity patterns (Su et al. 2004, Imai et al. 2012) and robust in indicating the response of tree assemblage to forest degradation due to anthropogenic disturbances (Imai et al. 2012, 2014). Measuring tree community composition is cost effective for REDD+, because only upper canopy trees are to be measured, making it cheaper than biodiversity metrics based on wildlife monitoring (Imai et al. 2014). Our results demonstrated that the relationship between $A G B$ and NMDS axis 1 based on field data (Fig. 5a) can be successfully reconstructed with the estimated AGB from satellite imagery (Fig. 5b). The intact and degraded forests were clearly separable at a value lower than the widely used AGB threshold of $200 \mathrm{Mg}^{-1}$ (Asner 2002, Morel et al. 2012). The difference could be due to the fact that the AGB of a montane rainforest is usually lower than that of a lowland rainforest (Aiba \& Kitayama 1999). Further in-depth study is needed to examine the application of this tree-centric approach as well as the AGB thresholds of forest degradation for different natural forest types using high-resolution satellite remote sensing. More generally, there is currently great interest in using remote sensing products to help monitor biodiversity (Skidmore et al. 2015). Incorporating remotely sensed maps of forest disturbance into biodiversity modelling efforts is likely to increase predictive power considerably.

\section{Conclusions}

Tropical forest biomass estimation using high-resolution satellite imageries has been receiving increasing attention, but its application to montane rainforests has not been adequately dealt with. Our results indicate that the use of high-resolution satellite imagery is useful in developing DBH estimation models, which can be used to estimate the AGB for intact and degraded montane rainforests in Northern Borneo. The crown area from the IKONOS-2 imagery was useful in estimating DBH for the intact and degraded forests, from which biomass can be estimated using published allometric equations.

Biodiversity safeguarding has been an important issue in REDD+ implementation in the tropics. The observed relationship between $A_{G B}$ and the NMDS axis 1, an index of tree community dissimilarity, showed that intact and degraded forests were well differentiated, allowing to use our $A_{G B}$ maps to map degradation. Tropical biodiversity should be examined in parallel with $A G B$ estimation using satellite remote sensing, because this kind of inferential information is useful in guiding REDD+ activities that are related to conservation of forest carbon stocks, sustainable management of forests and enhancement of forest carbon stocks.

\section{Acknowledgements}

This project was funded by Ministry of Agriculture, Forestry and Fisheries Research Council, Government of Japan. Ministry of Higher Education, Government of Malaysia provided "Geran Sanjungan Penyelidikan" that motivates us for strengthening our international collaborations. We sincerely thank the Sabah Forestry Department (SFD) for research permission, the
Sabah Forest Industry (SFI) for field support, and the Government of United States of America for some technical assistance.

\section{References}

Aiba S, Kitayama K (1999). Structure, composition and species diversity in an altitude-substrate matrix of rain forest tree communities on Mount Kinabalu, Borneo. Plant Ecology 140: 139-157. - doi: 10.1023/A:1009710618040 Anderson MJ (2001). A new method for nonparametric multivariate analysis of variance. Austral Ecology 26: 32-46. - doi: 10.1111/j.1442-99 93.2001.01070.pp.x

Asner GP (2002). Estimating canopy structure in an Amazon forest from laser finder and IKONOS satellite observations. Biotropica 34: 483492. - doi: 10.1111/j.1744-7429.2002.tboo568.x

Asner GP, Warner AS (2003). Canopy shadow in IKONOS satellite observations of tropical forests and savannas. Remote Sensing of Environment 87: 521-533. - doi: 10.1016/j.rse.2003.08.0 06

Asner GP, Powell GV, Mascaro J, Knapp DE, Clark JK, Jacobson J, Kennedy-Bowdoin T, Balaji A, Paez-Acosta G, Victoria E, Secada L, Valqui $M$, Hughes RF (2010). High-resolution forest carbon stocks and emissions in the Amazon. Proceedings of the National Academy of Sciences USA 107: 16738-16742. - doi: 10.1073/pnas.1004 875107

Asner GP, Mascaro J (2014). Mapping tropical forest carbon: calibrating plot estimates to a simple LiDAR metric. Remote Sensing of Environment 140: 614-624. - doi: 10.1016/j.rse.2013. 09.023

Bartelink HH (1996). Allometric relationship on biomass and needle of Douglas-fir. Forest Ecology and Management 86: 193-203. - doi: 10.1016 /S0378-1127(96)03783-8

Basuki TM, Van Laake PE, Skidmore AK, Hussin YA (2009). Allometric equations for estimating the above-ground biomass in tropical lowland Dipterocarp forests. Forest Ecology and Management 257: 1684-1694. - doi: 10.1016/j.foreco. 2009.01.027

Broadbent EN, Asner GP, Pena-Claros M, Palace $M$, Soriano M (2008). Spatial portioning of biomass and diversity in a lowland Bolivian forest: linking field and remote sensing measurements. Forest Ecology and Management 255: 2602-2616. - doi: 10.1016/j.foreco.2008.01.044 Broich M, Hansen MC, Potapov PV, Wimberley M (2013). Patterns of tree cover loss along the Indonesia-Malaysia border on Borneo. International Journal of Remote Sensing 34 (16): 57485760. - doi: 10.1080/01431161.2013.796099 Brown S (2002). Measuring carbon in forests: current status and future challenges. Environmental Pollution 116: 363-372. - doi: 10.1016/S02 69-7491(01)00212-3

Chao A, Chazdon RL, Colwell RK, Shen TJ (2005). A new statistical approach for assessing similarity of species composition with incidence and abundance data. Ecology Letters 8: 148-159. doi: 10.1111/j.1461-0248.2004.00707.x

Chave J, Réjou-Méchain M, Búrquez A, Chidumayo E, Colgan MS, Delitti WBC, Duque A, Eid T, Fearnside PM, Goodman RC, Henry M, Martínez-Yrízar A, Mugasha WA, Muller-Landau HC, Mencuccini M, Nelson BW, Ngomanda A, No- 
gueira EM, Ortiz-Malavassi E, Pélissier R, Ploton $P$, Ryan CM, Saldarriaga JG, Vieilledent G (2014). Improved allometric models to estimate the aboveground biomass of tropical trees. Global Change Biology 20: 3177-3190. - doi: 10.1111/gcb. 12629

Chavez PS (1988). An improved dark object subtraction technique for atmospheric scattering correction of multispectral data. Remote Sensing of Environment 24: 459-479. - doi: 10.1016/ 0034-4257(88)90019-3

Clinton N, Holt A, Scarborough J, Li Y, Peng G (2010). Accuracy assessment measures for object-based image segmentation goodness. Photogrammetric Engineering and Remote Sensing 76: 289-299. - doi: 10.14358/PERS.76.3.289

Culvenor DS (2003). Extracting individual tree information: a survey of techniques for high spatial resolution imagery. In: "Forest Environments: Concepts and Case Studies" (Wulder MA, Franklin SE eds). Kluwer Academic Publishers, Boston, MA, USA, pp. 255-277. - doi: 10.1007 /978-1-4615-0306-4_9

Dalponte M, Coomes DA (2016). Tree-centric mapping of forest carbon density from airborne laser scanning and hyperspectral data. Methods in Ecology and Evolution. - doi: 10.1111/ 2041-210X.12575

Dickson B, Kapos V (2012). Biodiversity monitoring for REDD+. Current Opinion in Environmental Sustainability 4: 590-596. - doi: 10.1016/j.co sust.2012.09.017

Gardner TA, Burgess ND, Aguilar-Amuchastegui N, Barlow J, Berenguer E, Clements T, Danielsen F, Ferreira J, Foden W, Lees AC, RomanCuesta RM, Parry L, Schmitt CB, Strange N, Khan SM, Theilade I, Vieira ICG (2012). A framework for integrating biodiversity concerns into national REDD+ programmes. Biological Conservation 154: 61-71. - doi: 10.1016/j.biocon.2011. 11.018

Gaveau DLA, Sloan S, Molidena E, Yaen H, Sheil D, Abram NK, Ancrenaz M, Nasi R, Quinones M, Wielaard N, Meijaard E (2014). Four decades of forest persistence, clearance and logging on Borneo. PLoS ONE 9 (7): e101654. - doi: 10.1371/ journal.pone.0101654

Gougeon FA, Leckie DG (2006). The individual tree crown approach applied to Ikonos images of a coniferous plantation area. Photogrammetric Engineering and Remote Sensing 72: 1287-1297. - doi: 10.14358/PERS.72.11.1287

Hirata Y, Tsubota Y, Sakai A (2009). Allometric models of $\mathrm{DBH}$ and crown area derived from QuickBird panchromatic data in Cryptomeria japonica and Chamaecyparis obtuse stands. International Journal of Remote Sensing 30: 50715088. - doi: 10.1080/01431160903022977

Imai N, Seino T, Aiba S, Takyu M, Titin J, Kitayama K (2012). Effects of selective logging on tree species diversity and composition of Bornean tropical rain forests at different spatial scales. Plant Ecology 213: 1413-1424. - doi: 10.100 7/s11258-012-0100-y

Imai N, Tanaka A, Samejima H, Sugau JB, Pereira JT, Titin J, Kurniawan Y, Kitayama K (2014). Tree community composition as an indicator in biodiversity monitoring of REDD+. Forest Ecology and Management 313: 169-179. - doi: 10.1016/j. foreco.2013.10.041

Ioki K, Tsuyuki S, Hirata Y, Phua MH, Wong W,
Ling ZY, Saito H, Takao G (2014). Estimating aboveground biomass of tropical rainforest of different degradation levels in Northern Borneo using airborne lidar. Forest Ecology and Management 328: 335-341. - doi: 10.1016/j.for eco.2014.06.003

IPCC (2006). IPCC Guidelines for National Greenhouse Gas Inventories. Institute for Global Environmental Strategies, Japan, pp. 20.

Kenzo T, Ichie T, Hattori D, Itioka T, Handa C, Ohkubo T, Kendawang JJ, Nakamura M, Sakaguchi M, Takahashi N, Okamoto M, Tanaka-Oda A, Sakurai K, Ninomiya I (2009). Development of allometric relationships for accurate estimation of above-ground biomass in tropical secondary forests in Sarawak, Malaysia. Journal of Tropical Ecology 25: 371-386. - doi: 10.1017/So2 66467409006129

Langner A, Samejima H, Ong RC, Titin J, Kitayama K (2012). Integration of carbon conservation into sustainable forest management using high resolution satellite imagery: a case study in Sabah, Malaysian Borneo. International Journal of Applied Earth Observation and Geoinformation 18: 305-312. - doi: 10.1016/j.jag.2012.02. 006

Le Quere C, Raupach MR, Canadell JG, Marland G, Bopp L, Ciais P, Conway TJ, Doney SC, Feely $\mathrm{RA}$, Foster $\mathrm{PN}$, Friedlingstein $\mathrm{P}$, Gurney $\mathrm{K}$, Houghton RA, House J, Huntingford C, Levy PE, Lomas MR, Majkut J, Metzl N, Ometto JP, Peters GP, Prentice IC, Randerson JT, Running SW, Sarmiento JL, Schuster U, Sitch S, Takahashi T, Viovy N, Van Der Werf GR, Woodward FI (2009). Trends in the sources and sinks of carbon dioxide. Nature Geoscience 2: 831-836. doi: 10.1038/ngeo689

Leckie DG, Gougeon FA, Walsworth N, Paradine D (2003). Stand delineation and composition estimation using semi-automated individual tree crown analysis. Remote Sensing of Environment 85: 355-369. - doi: 10.1016/So0344257(03)00013-0

Leckie DG, Gougeon FA, Tinis S, Nelson T, Burnett CN, Dennis P (2005). Automated tree recognition in old growth conifer stands with high resolution digital imagery. Remote Sensing of Environment 94: 311-326. - doi: 10.1016/j. rse.2004.10.011

Lu D (2005). Aboveground biomass estimation using Landsat TM data in the Brazilian Amazon. International Journal of Remote Sensing 26: 2509-2525. - doi: 10.1080/01431160500142145

Malhi Y, Grace J (2000). Tropical forests and atmospheric carbon dioxide. Trends in Ecology and Evolution 15: 332-337. - doi: 10.1016/S01695347(00)01906-6

Morel AC, Fisher JB, Malhi Y (2012). Evaluating the potential to monitor aboveground biomass in forest and oil palm in Sabah, Malaysia, for 2000-2008 with Landsat ETM+ and ALOS-Palsar. International Journal of Remote Sensing 33: 3614-3639. - doi: 10.1080/01431161.2011.631 949

Murray JP, Grenyer R, Wunder S, Raes N, Jones JPG (2015). Spatial patterns of carbon, biodiversity, and REDD+ projects in Indonesia. Conservation Biology 29: 1434-1445. - doi: 10.1111/cobi. 12500

Oksanen J, Blanchet FG, Kindt R, Legendre P, Minchin PR, O'Hara RB, Simpson GL, Solymos P,
Stevens MHH, Wagner H (2013). Vegan: community ecology package. Web site. [online] URL: http://cran.r-project.org/package=vegan Palace M, Keller M, Asner GP, Hagen S, Braswell $B$ (2008). Amazon forest structure from IKONOS satellite data and the automated characterization of forest canopy properties. Biotropica 40: 141-150. - doi: 10.1111/j.1744-7429.2007.0035 $3 . x$

Pitkanen J (2001). Individual tree crown detection in digital aerial images by combining locally adaptive binarization and local maxima methods. Canadian Journal of Forest Research 31 (5): 832-844. - doi: 10.1139/x01-013

Phua $\mathrm{MH}$, Saito H (2003). Estimation of biomass of a mountainous tropical forest using Landsat TM data. Canadian Journal of Remote Sensing 29: 429-440. - doi: 10.5589/mo3-005

Phua MH, Ling ZY, Wong W, Korom A, Ahmad B, Besar NA, Tsuyuki S, loki K, Hoshimoto K, Hirata Y, Saito H, Takao G (2014). Estimation of aboveground biomass of a tropical forest in northern Borneo using high-resolution satellite image. Journal of Forest and Environmental Science 30: 233-242. - doi: 10.7747/JFS.2014-30.2.233

Pouliot D, King D (2005). Approaches for optimal automated individual tree crown detection in regenerating coniferous forests. Canadian Journal of Remote Sensing 31: 255-267. - doi: 10.5589/mo5-011

Skidmore AK, Pettorelli N, Coops NC, Geller GN, Hansen M, Lucas R, Mücher CA, O'Connor B, Paganini M, Pereira HM, Schaepman ME, Turner W, Wang T, Wegmann M (2015). Environmental science: agree on biodiversity metrics to track from space. Nature 523 (7561): 403405. - doi: 10.1038/523403a

Sheil D, Burslem DFRP (2003). Disturbing hypotheses in tropical forests. Trends in Ecology and Evolution 18: 18-26. - doi: 10.1016/S01695347(02)00005-8

Smith JA, Lin TL, Ranson KJ (1980). The Lambertian assumption and Landsat data. Photogrammetric Engineering and Remote Sensing 46: 1183-1189. [online] URL: http://www.research gate.net/publication/247923568

Song C, Dickinson MB, Su L, Yaussey D (2010). Estimating average tree crown size using spatial information from IKONOS and Quickbird images: across sensor and across-site comparisons. Remote Sensing of Environment 114: 1099-1107. - doi: 10.1016/j.rse.2009.12.022

Stern N (2007). The economics of climate change: the Stern review. Cambridge University Press, Cambridge, UK, pp. 712. - doi: 10.1017/So021932008002824

Su JC, Debinski DM, Jakubauskas ME, Kindscher $\mathrm{K}$ (2004). Beyond species richness: community similarity as a measure of cross-taxon congruence for coarse-filter conservation. Conservation Biology 18: 167-173. - doi: 10.1111/j.1523-1739. 2004.00337.x

Vermote EF, El-Saleous N, Justice CO, Kaufman YJ, Privette JL (1997). Atmospheric correction of visible to middle-infrared EOS-MODIS data over land surfaces: background, operational algorithm, and validation. Journal of Geophysical Research 102: 17131-17141. - doi: 10.1029/97J Do0201

Visseren-Hamakers I, McDermott C, Vijge $M$, Cashore B (2012). Trade-offs, co-benefits and 
safeguards: current debates on the breadth of REDD+. Current Opinion in Environmental Sustainability 4: 590-596. - doi: 10.1016/j.cosust.20 12.10.006

Wulder MA, White JC, Niemann KO, Goodenough DG (2002). Error reduction methods for local maximum filtering of high spatial resolution imagery for locating trees. Canadian Journal of Remote Sensing 28: 621-628. - doi: 10.558 9/mo2-059

Wang L, Gong P, Biging G (2004). Individual tree crown delineation and tree top detection in high spatial resolution aerial imagery. Photogrammetric Engineering and Remote Sensing 70: 351-357. - doi: 10.14358/PERS.70.3.351

Yamakura T, Hagihara A, Sukardjo S, Ogawa H (1986). Aboveground biomass of tropical rain forest stands in Indonesian Borneo. Vegetatio
68: 71-82. [online] URL: http://link.springer. com/article/10.1007/BFo0045057

Zanne AE, Lopez-Gonzalez G, Coomes DA, Ilic J, Jansen S, Lewis SL, Miller RB, Swenson NG, Wiemann MC, Chave J (2009). Data from: Towards a worldwide wood economics spectrum. Dryad Digital Repository. - doi: 10.5061/dryad. 234 